The Michigan Infant Mental Health Home Visiting Model

Deborah J. Weatherston $\mathrm{PhD}^{1}$, Julie Ribaudo, $\mathrm{LMSW}^{2}$, and the Michigan Collaborative for Infant Mental Health Research ${ }^{3}$

${ }^{1}$ Consultant, Alliance for the Advancement of Infant Mental Health

${ }^{2}$ University of Michigan/School of Social Work

${ }^{3}$ The Michigan Collaborative for Infant Mental Health Research (MCIMHR) is comprised of researchers from eight universities and from the Alliance for the Advancement of Infant Mental Health, each of whom have collaborated in the design and implementation of the current study. MCIMHR members include (in alphabetical order): Holly Brophy-Herb, Hiram Fitzgerald, Alissa Huth-Bocks, Jennie Jester, Megan Julian, Jamie Lawler, Alyssa Meuwissen, Maria Muzik, Larissa Niec, Julie Ribaudo, Katherine L Rosenblum, Sarah Shea, Paul Spicer, Ann Stacks, Laurie Van Egeren, Christopher Watson, Deborah Weatherston.

We gratefully acknowledge that this research was made possible through the financial support provided by the Michigan Department of Health and Human Services, the Ethel and James Flinn Foundation, the Gerstacker Foundation, the University of Michigan's Women and Infants Mental Health Program, and the Michigan Department of Health and Human Services Children's Mental Health Block Grant (K. Rosenblum and M. Muzik, PIs).

Note: The authors, Deborah Weatherston and Julie Ribaudo, have worked collaboratively for over 30 years. This paper reflects their shared commitment to the infant mental health field. They dedicate this paper to William "Bill" Schafer whose training and consultation nurtured the growth of the Infant Mental Health Home Visiting services in Michigan for over 40 years.

This is the author manuscript accepted for publication and has undergone full peer review but has not been through the copyediting, typesetting, pagination and proofreading process, which may lead to differences between this version and the Version of Record. Please cite this article as doi:

10.1002/imhj.21838.

This article is protected by copyright. All rights reserved. 


\begin{abstract}
:
Selma Fraiberg's pioneering work with infants, toddlers and families over 40 years ago led to the development of a field in which professionals from multiple disciplines learned to work with or on behalf of infants, very young children, their parents, and the relationships that bind them together. The intent was to promote social and emotional health through enhancing the security of early developing parent-child relationships in the first years of life (Fraiberg, 1980). Called Infant Mental Health (IMH), practitioners from fields of health, education, social work, psychology, human development, nursing, pediatrics and psychiatry specialize in supporting the optimal development of infants and the developing relationship between infants and their caregivers. When a baby is born into optimal circumstances, to parents free of undue economic and psychological stressors and who are emotionally ready to provide care and nurturing for an infant's needs, an IMH approach may be offered as promotion or prevention, with the goal of supporting new parent(s) in developing confidence in their capacity to understand and meet the needs of the tiny human they are coming to know and care for. However, when parental history is fraught with abandonment, loss, abuse or neglect, or the current environment is replete with economic insecurity, threats to survival due to interpersonal or community violence, social isolation, mental illness or substance abuse, the work of the IMH therapist may require intervention or intensive treatment and becomes more psychotherapeutic in nature. The underlying therapeutic goal is to create a context in which the baby develops within the context of a parent's nurturing care without the psychological impingement that parental history of trauma or loss or current stressors such as isolation, poverty or the birth of a child with special needs, can incur.
\end{abstract}

Key words: Fraiberg, infant mental health, infant parent psychotherapy, home visiting, parent infant relationships

This article is protected by copyright. All rights reserved. 
Three key findings:

1. This paper presents a brief history of the origins of the Michigan Infant Mental Health Home Visiting model as developed by Selma Fraiberg and her colleagues in the early 1970's.

2. The authors provide an overview of the theoretical underpinnings and core strategies of the Infant Mental Health Home visiting model: building an alliance, material needs, emotional support, infant-parent psychotherapy, life coping skills and social supports.

3. The authors discuss reflective supervision, and its integral role in strengthening the therapist's capacity for observation, empathy, compassion, and responsivity, while holding the baby, the parent, and multiple relationships in mind.

Relevance to the field: This article describes in detail the Infant Mental Health Home Visiting model, a relationship centered, preventive intervention and treatment service that offers developmental and clinical support to strengthen an infant's social and emotional wellbeing and a parent's mental health, reducing the significant risk of disorder or delay and enhancing the capacity for relationship health.

\section{The Beginnings}

In the early 1970 's, under Selma Fraiberg's careful direction, social workers, psychologists, nurses, and psychiatrists worked side by side in Ann Arbor, Michigan to create a specialized service to offer preventive intervention and psychological treatment on behalf of babies, parents, and their developing parent-child relationships. Understanding that the best beginning for a baby takes place within the context of at least one nurturing relationship, Fraiberg and her interdisciplinary team placed the early relationship between parent and infant at the center of the work of infant mental health. "Infant" provided the focus on very young children, under 3 years of age. "Mental" was

This article is protected by copyright. All rights reserved. 
broadly defined to include social, emotional and cognitive domains. "Health" emphasized the wellbeing of infants and toddlers, as well as the health of their parents as they prepare for or care for their infant. (Fraiberg, 1980).

Believing that the infant could not call a mental health clinic and say, "I am having a difficult time!" or "My mother is in crisis and cannot hold or feed me!" or "My Father is hitting my mother!" and understanding that the referred depressed or vulnerable parents may not have the means or capacity to attend an out-patient clinic, or to otherwise reach out, the early infant mental health specialists were prepared to bring their services into each infant and family's home, visiting weekly (for at least an hour) or more frequently during a crisis. They called their work "kitchen table therapy" (Fraiberg, 1980; Weatherston, 2012). Busy developing the model, and prior to the demand for an evidence base, Fraiberg and her team, notably Vivian Shapiro and Edna Adelson, and including William Schafer and Jeree Pawl, contributed to the development of the field through the training of a new generation of clinicians and leaders, including Douglas Davies, Alicia Lieberman, Michael Trout, and Barry Wright among others, and, subsequently, an impressive array of substantive articles.

Fraiberg left the University of Michigan in 1979 and relocated to the University of California at San Francisco together with Michigan colleagues, Drs. Jeree Pawl and Alicia Lieberman. Fraiberg was diagnosed with a brain tumor in August 1981 and died in December 1981 at the age of 63 (Brown, 2009). Her work and the original IMH-HV model served as the initial template for both the Infant-Parent Program, training therapists in the art of infant-parent psychotherapy (IPP), and ChildParent Psychotherapy (CPP), developed and studied by Lieberman and Van Horn (2004) in California. At that same time, in Michigan, with funding from the Michigan Department of Mental Health and under the direction of Betty Tableman, Director of Prevention Services, the specialization of IMH home visiting services was delivered to pregnant or parenting women, infants and their families through Michigan's community mental health system. (see this Special Issue, Tableman). The Michigan model was carefully implemented across the state by policy makers and practitioners who This article is protected by copyright. All rights reserved. 
believed in preventive intervention to reduce the risk of developmental and clinical disturbances in infancy and early parenthood and to enhance the caregiving competencies of parents. Infant

mental health specialists across the state established a professional organization in 1977, the Michigan Association for Infant Mental Health, to provide training and support to refine, implement, and advocate for infant mental health across service systems. In 1989, Weatherston and Tableman described the model in great detail in their manual Infant Mental Health Home Visiting: Supporting Competencies/Reducing Risks (Weatherston \& Tableman, 1989).

A novel integration of IMH services into Early Head Start (IMH-HB EHS) home visiting was piloted in the 1990s. As part of the model, EHS home visitors received 36 hours of training, plus 3 hours monthly of reflective supervision (RS) (McKelvey, et al., 2015). At the end of services, and at follow up when the children were 7 years old, parents randomly assigned to the IMH-HB EHS model reported less parenting stress than the comparison group and a small but significant effect was seen in increased positive parent-child relationships. Other home visiting services, e.g., Healthy Families America (Harding, Galano, Martin, Huntington, \& Schellenbach, 2007), combine education with an intentional focus on the early developing relationship, parenting, and, more recently, the integration of IMH principles into their staff training experiences. As relationship-based interventions gain a strong evidence base, even settings like neonatal intensive care units are utilizing some components, such as reflective supervision/consultation to train and support staff (Ash \& Williams, 2016).

Through the years, other home visiting models built upon Fraiberg's work and were developed to offer intensive mental health intervention including Child First (Lowell, Carter, Godoy, Paulicin, \& Briggs-Gowan, 2011) and Minding the Baby (Sadler, et al. 2013). Both focused specifically on supporting parental reflective capacity, sensitive caregiving, and promoting a secure attachment relationship. Both adapted many of the core therapeutic principles and practices embedded in Fraiberg's original IMH model, including the provision of psychodynamically oriented infant-parent psychotherapy and attention to concrete support. These programs are evidence-based, aim to 
reduce the risks of developmental delay in infancy or parental depression, abuse or neglect in early parenthood, and are delivered during pregnancy into a child's first 3 years if clinically indicated.

When intensive treatment is necessary in response to identified disorders of infancy or identified mental health or behavioral health disorders in the caregiving parent, especially in the context of severe and ongoing trauma, an intensive program such as Child-Parent Psychotherapy (CPP) (Lieberman, \& Van Horn, 2005) may be the treatment of choice. Originally piloted as an intervention for 3 to 5 year old children, but now also a model for treating infants and toddlers, CPP, a trauma-specific parent-child treatment model, is an extension of IPP and emphasizes the "child's centrality as an active partner in the treatment by focusing on the child's emotional experience and embedding this experience in the child-parent relationship" (Lieberman, 2004, p. 98).

What is most characteristic of the Michigan IMH-HV model? Situated in the family's home, the IMH-HV therapist sits with the infant and parent together, observing what each brings to the other in their relationship and listening carefully to what parents have to say, mindful of the thoughts and emotions awakened by the presence of a baby and the gentle, careful therapist. By observing and listening, staying open to both the pleasures and the pains, the therapist joins the infant and parent in creating a space where they come to know one another. It is in this safe space that the IMH-HV therapist and parent together can observe, wonder about, explore, and understand the attachment relationship between the parent and infant. In the safety of the therapeutic relationship, parents may have and express thoughts and feelings about their babies, the complexities of parenthood, as well as more immediate hopes, worries, and concerns. They may also share stories about themselves that affect their ability to care for their very young children - experiences, past and present, including abandonment, loss, separation, trauma, abuse, and neglect. This approach is described as "multifaceted, needs driven and relationship-focused," (Rosenblum, et al., under review), incorporating both clinical and developmental strategies to address social and emotional wellbeing, emerging caregiving capacities, maternal mental health, and reflective functioning, all fundamental to the Michigan IMH HV model.

This article is protected by copyright. All rights reserved. 


\section{THEORETICAL UNDERPINNINGS TO THE MICHIGAN}

IMH HOME VISITING MODEL

"In every nursery there are ghosts" (Fraiberg, Adelson \& Shapiro, 1975). So began the seminal article describing the theoretical underpinnings and methodology of the Infant Mental Health program that Fraiberg and her team developed. Conceptually derived from psychoanalytic theory, attachment theory, social work practice and developmental psychology, the Child Development Project team sought to understand the mechanisms by which some parents were able to care for their infants in spite of overwhelming odds, some intrapsychic (e.g., their own unresolved trauma) and some environmental (e.g., living in poverty). They sought to understand how to free the "baby in peril" (Fraiberg, et al., 1975, pg. 403) from the ghosts of the parent's past. Psychoanalytic principles, such as understanding the defense mechanisms by which a parent protects themselves from overwhelming anxiety, and social work principles, such as incorporating the context in which a family resides, wove together to define this new and unusual approach to preventing and/or addressing child maltreatment, emotional deprivation and other barriers to parents and their baby falling in love. The core strategies they elaborated over time included: building an alliance or working relationship, providing for material needs, offering emotional support, providing developmental guidance, engaging in infant-parent psychotherapy, and developing life coping skills and social support (Shapiro, 2009; Weatherston \& Tableman, 2015).

This article is protected by copyright. All rights reserved. 


\begin{tabular}{|l|l|}
\hline Component & Example \\
\hline Building an alliance & $\begin{array}{l}\text { "Listened to and accepted mother's feeling about family } \\
\text { criticism of her parenting" }\end{array}$ \\
\hline $\begin{array}{l}\text { Material needs } \\
\text { Eevelopmental } \\
\text { guidance }\end{array}$ & $\begin{array}{l}\text { "Helped family obtain material needs including food, and a crib } \\
\text { for the baby" }\end{array}$ \\
\hline $\begin{array}{l}\text { Infant-Parent } \\
\text { Psychotherapy }\end{array}$ & $\begin{array}{l}\text { "Supported parents/family during eviction process" } \\
\text { injured" } \\
\text { "Addressed the feelings of vulnerability that arise when the } \\
\text { comforted when she was sad" }\end{array}$ \\
\hline $\begin{array}{l}\text { Life coping skills and } \\
\text { social supports }\end{array}$ & $\begin{array}{l}\text { "Showed interest in father's experience of a new fathering } \\
\text { mentoring group he joined" and "Addressed issues related to } \\
\text { mother's depression, including validating her commitment to } \\
\text { psychiatric treatment" }\end{array}$ \\
\hline
\end{tabular}

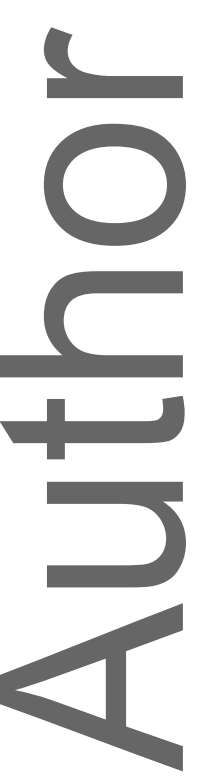

Table 1. Core components of infant mental health treatment

The concept of "ghosts in the nursery" is worthy of particular attention in considering the theoretical basis for infant-parent psychotherapy. Fraiberg described the ways in which the psyche of parents influenced the quality of the parent-child relationship. Of particular interest were parents who seemed unable to "see" their infant and who conveyed distorted perceptions of the baby, perhaps seeing the baby as evil or "out to get" the parent and thought to represent a ghost from the parent's past, e.g., unresolved trauma. Fraiberg, Adelson and Shapiro (1975) posited that parents who could not "own" or remember the feelings of helplessness, fear and rage that they experienced at the hands of their own caregivers often saw their baby as a source of threat. In such instances, the parent unconsciously identifies with the earlier aggressor and becomes the "victimizer" in the current relationship (Lieberman \& Van Horn, 2008). For example, a mother might perceive that her unborn child kicks her on purpose, projecting onto the child the image of a powerful sibling or 
caregiver who was aggressive or harmful in her childhood. Once born, the baby's vulnerability is unconsciously but selectively overlooked, while the mother perceives his flailing and wailing as

intentionally aggressive and responds with her own harshness, aggression or withdrawal. Benoit, Parker \& Zeanah (1997) found that parents' internal representations of their baby, in utero, is significantly correlated with attachment outcomes by 12 months of age. The caregiver's selective attention and misperception of the infant's cues then begins to shape the infants' sense of self and their expectations of others (Sameroff, 2004). As the child ages, he is at heightened risk of the internalizing of the parent's perception of himself as aggressive (Winnicott, 1971; Lyons-Ruth, 1996). The accumulation of frustration and "interpersonal alienation and anger" (Sroufe, Egeland, Carlson, \& Collins, 2005, p. 256) can lead to early manifestations of conduct disorders (Sroufe, et al., 2005; Lyons-Ruth, 1996).

During the 1960 's, Bowlby was elucidating the fundamental role of attachment in the development of emotional health and well-being of infants (Bowlby, 1969/1982). He posited that children in the first years of life develop "internal working models" of attachment based on the nature of their day-to-day interactions with their caregiver. Working models are mental maps of the self and primary attachment figures and thought to help the developing infant predict how interactions go between himself and his primary caregivers, especially in times of alarm or distress (Bowlby, 1969/1982; Sherman, Rice and Cassidy, 2015). Being able to develop experience-based expectations of the self and others in attachment-related interchanges frees the baby from having to construct a new set of interactional "rules" for each exchange with primary caregivers. Eventually, the working models of interactive exchanges coalesce into patterns of attachment (Bowlby, 1969/1982). Longitudinal studies have illuminated the influence of early attachment in adolescent development, as well as adult romantic relationships and health outcomes (Sroufe, et al., 2005; Sroufe, 2013; Raby, Lawler, Shlafer, Hesemeyer, Collins, \& Sroufe, 2015; Puig, Englund, Simpson, \& 
Collins, 2013) and the intergenerational transmission of these patterns of interaction (Sroufe, et al., 2005; Lyons-Ruth, Yellin, Melnick, \& Atwood, 2003; Raby, et al. 2015).

More recent literature has illuminated the role of the parent-infant relationship in developing the neurobiology and architecture of the brain. Schore notes that "traumatic dysregulating levels of relational stress during the early stages of life exert an enduring detrimental epigenetic impact on the developing right brain, significantly altering the individual's emotional responsiveness and stress-coping strategies later in life" (2017, p. 22). Parents who lack implicit procedural memories (Schore, 2000) of being cared for in times of alarm or stress themselves risk becoming overwhelmed in the face of their infants' distress, which can result in disruptive responses to the baby and thus continue the intergenerational cycle of mis-attuned, insensitive caregiving (Lyons-Ruth, et al., 2003). Additionally, harsh and frightening parenting, often rooted in the caregiver's own early history of unresolved fright, can contribute to the baby's ongoing experience of the parent being a source of alarm (Lyons-Ruth, 1996; Lyons-Ruth, et al., 2003).

\section{Core Intervention Strategies of the Michigan IMH Home Visiting Model}

Today, as in the early work of Fraiberg and her team, infant mental health home visiting (IMH-HV) therapists use a variety of core intervention strategies to support the development of the infant within the context of nurturing relationships, to reduce the risk of developmental delays or relationship disturbances or disorders of infancy, and to enhance parental caregiving capacities. These strategies or core components are individualized depending on the unique needs of each infant and family referred. Each strategy supports the early developing attachment relationship between parent and child and includes the following: building an alliance or working relationship, providing for material needs, offering emotional support, providing developmental guidance, engaging in infant-parent psychotherapy, and developing life coping skills and social support. (Shapiro, 2009; Weatherston, Weigand, \&Weigand, 2010, Weatherston \& Tableman, 2015). The development of a strong, trusting, and stable working relationship between parent and IMH

This article is protected by copyright. All rights reserved. 
therapist is fundamental to a successful IMH-HV intervention. With a working alliance as the foundation for service, the IMH therapist may introduce one, several or all of the other strategies, according to the needs of each infant, toddler, and family referred (Weatherston, 1995). What follows is a description of the core strategies, beginning with the working relationship, that are significant to the support of infant development, parental competency, and the reduction of social, emotional, and behavioral risk in infancy and early childhood.

\section{Building A Working Relationship}

The working relationship is central to the success of an IMH-HV intervention. From the first contact, to the first visit and in those that follow, the IMH-HV therapist holds in mind the power of relationships to effect change. The IMH-HV therapist is respectful of the parent's willingness to meet on behalf of the baby's wellbeing and acknowledges the courage it takes to share worries or concerns about the baby or discuss the uncertainty of caregiving and the complexity of their lives.

Consciously or not, parents take a tremendous risk letting a stranger, the therapist, into their homes. For parents who have had "good enough" (D.W. Winnicott, 1953, p. 94) caregiving, the home visitor might be a welcome companion, seen almost immediately as a source of support, information, and comfort. Such may not be the beginning psychological stance for mothers and fathers who have suffered at the hands of caregivers or systems (Ghosh Ippen, 2019). The sense of trust and emotional safety needed to explore their reactions to their babies, to reveal their sense of inadequacy, anger or helplessness in words instead of action, and to experience the IMH-HV therapist as a source of nurturing and support, may develop slowly. The therapist must be steady, reliable, available, predictable, compassionate, and responsive in order for the relationship with parents to flourish, and even with all of those traits, the formation of a strong therapeutic relationship can be agonizingly slow. The therapist's response to the family's immediate needs for food, formula, housing, health care, child care, to name a few, as well as his or her response to the This article is protected by copyright. All rights reserved. 
need for emotional support due to current stressors, contributes to the building of a strong and stable working relationship. In proving that the IMH-HV therapist can meet the basic needs of the infant and family, the relationship strengthens. In addition, the therapist must pay attention to the cultural forces, including racism and discrimination, that shape the attitudes, values and beliefs that guide a parent's behavior and the home visitor's assumptions (Ghosh Ippen, 2019). Without attention to the broader cultural context in which the family resides, the IMH-HV therapist runs the risk of reinforcing societal messages that derail a parent's trust in the home visitor and reinforce systems of dominance, privilege and oppression that have created inequity and epistemic mistrust (Irving Harris Foundation Professional Development Network Tenets Working Group, 2018; Knox, 2016).

General principles behind building this working relationship include observing the parent and infant together so that they feel seen; listening so that the parent and infant feel heard; the offer of warm and positive emotional response to the realities of the moment; respect for the parent's wish to be a better parent; non-judgmental acceptance of the parent's vulnerabilities and pain; acceptance and understanding of the challenges and complexities of the infant and family's lives (McDonough, 2004). It is in this safe, caring, holding relationship with the therapist that parents can begin to observe, explore, and wonder about their baby, their experience of early caregiving, and share the worries about the baby that they may have. Of additional importance, and when feeling safe enough, the parents may begin to share the pain of their own relational losses abandonments, separations, abusive or neglectful care, removal to foster care. It is this relationship between the IMH-HV therapist and the parent that offers the possibility of growth and change for both the infant at risk and the parent referred (Suchman, DeCoste \& Mayes, 2009; Rosenblum, McDonough, Sameroff \& Muzik, 2008; Pawl, 1984; Fraiberg, Shapiro \& Cherniss, 1980). 


\section{Providing for Material Needs, Advocacy, and Health Care}

As referenced above, many families with infants or very young children who are referred for IMH-HV services have basic needs for food, clothing, shelter, child care and/or medical care.

Overwhelmed by poverty, they may feel helpless or hopeless in face of adversity. As a consequence, they may not be able to attend to the needs of their infants for attention or affection or nurturing care, leaving their young children at great risk for poor developmental outcomes and insecure attachment relationships. Facing extreme adversity, many families

need assistance in securing food, shelter, clothing and medical care to reduce the situational and environmental stress affecting the infants and toddlers in their care. For these families, the provision of case management services to assure the health, survival, and development of their young children is an essential component of the Michigan IMH-HV model. By attending to these concrete needs, the IMH-HV therapist seeks to reduce the impact of some of the most harmful social determinates of poor health, developmental, and relational outcomes. When unmet, these needs may make it extraordinarily difficult for parents to feed, nurture, and protect their children from harm. By responding to a family's needs, the IMH-HV therapist helps parents and infants to survive and, in turn, helps parents to offer appropriate care for their infants. Recognizing that the family is nested in their ecological system (Bronfenbrenner, 1977), the IMH therapist attends to the intrapsychic and environmental forces that press on the family system.

Basic to Michigan's IMH-HV model is the belief that parents who are hungry may not be able to nourish their infant or toddler's growth; parents who are cold may not be able to keep their young child warm; parents who are physically ill or chronically depressed may not respond with to the physical or emotional needs of their infant. The IMH-HV therapist's ability to help procure immediate needs to relieve the family's hunger or find shelter if homeless or identify a health care provider, strengthens the likelihood that the family will believe that the therapist can meet their needs and begin to trust the home visitor, entering into a strong and meaningful working

This article is protected by copyright. All rights reserved. 
relationship (Stern, 2004).

Finally, the IMH-HV therapist may act as an advocate in multiple service systems as needed by a parent or infant. The IMH-HV therapist has continuing responsibility to speak for those who cannot, to promote development of social, emotional, and relational health. The therapist must ask, "What about the pregnancy? What about the baby? What about the parent?"

Such advocacy requires working relationships with other community professionals. Coordination better assures that families who are referred by the IMH-HV therapist will receive prenatal or pediatric services from the public health nurse, health care for the parents from a family physician, substance abuse treatment, referral to an approved child care provider or referral to a child protective services worker in a timely manner. With basic needs attended to, the therapeutic work of the IMH service may be easier for parents to engage in together with their infants or toddlers in their home.

\section{Developing Social Support, Problem Solving Skills, and Life Course Planning}

Families referred to IMH-HV services are often isolated from family and friends. As a parent's capacity to enter into a strong working relationship with the IMH-HV therapist deepens, she or he may begin to resolve conflicts with family members, identify a neighbor who might become a friend, and develop meaningful relationships through participation in parent groups or other community services (McKelvey, et al., 2015). Stern (2004) notes the longing of new mothers to experience the interest and care of more experienced women to offer physical support and "to create a sort of holding environment in which the new mother feels encouraged, validated, appreciated and psychologically supported so that she, herself, can freely explore her own innately given repertoire of maternal behaviors" (p. 34).

This article is protected by copyright. All rights reserved. 


\section{Providing Emotional Support}

An IMH-HV therapist is often one of the only people to offer ongoing emotional support to a parent following a deeply distressing crisis, e.g. the birth of a premature infant, the hospitalization of a sick baby, abandonment by the baby's father, or the death of a parent or loved one. These immediate emotional challenges may make the care of an infant or young child difficult. Often distraught and overwhelmed, parents benefit from the presence of the IMH-HV therapist to help them survive the difficulties. The therapist is a careful observer, noticing all that is happening in the home, assessing the infant's strengths and needs and noticing the parent's individual caregiving capacities and limitations. She invites the parents to talk and listens closely, without interruption, to what they have to say. Attentive to the realities, thoughtful and nonjudgmental in response to the details shared, the IMH-HV therapist offers empathy in response to what she sees and hears during the home visit. Of additional importance, the therapist identifies and reinforces feelings that parents and infant have or express and, as necessary, sets limits so that parents are able to manage stressful situations and remain hopeful.

\section{Providing Developmental Guidance}

Developmental guidance as defined in the Michigan IMH-HV model uses a non-didactic approach, rooted in the shared observation of the infant or toddler at a pace that invites parents to observe what is going well, to be curious about their baby's development, and to voice their worries or concerns if they have them. A relational lens allows for individualized developmental guidance with an emphasis on observation, listening, wondering, and responding to the current demands of parenting.

The IMH-HV therapist may respond with information that is specific to the infant's or toddler's developing capacities, reinforcing positive parent-infant interactions and strengthening the developing attachment relationship. Every effort is made to support parental capacity to notice their

This article is protected by copyright. All rights reserved. 
child's development and behavior, i.e., be the expert about their own baby as they assimilate new information or discoveries, and, in the presence of the baby, grow curious, ask questions, wonder, and reflect (Cohen, et al., 1999; Weatherston \& Tableman, 2015; Weatherston, 2000). Inherent in this stance is the belief that parents who learn to be careful observers and listeners of their babies become better able to reflect on the meaning of behavior and to note and respond to developmental shifts throughout childhood (Fraiberg, 1980; Lieberman, 2018). Crucial to the model, information about early care, feeding, sleeping, or other areas of caregiving, is not driven by a fixed curriculum and never imposed on the parent. Rather, the IMH-HV therapist invites parents to discover their infant's or toddler's unique strengths and, at the same time, to acknowledge their own emerging caregiving capabilities. Such an approach invites reflective functioning (Slade, 2005) as the foundation for parental understanding and continued growth of the parent-child relationship long after the sound of the clinician's voice fades. Parental sensitivity to the unique needs of their baby is an important outcome of reflective process.

Important to note, the Michigan IMH-HV model encourages and highlights parental behavior and parent-child interaction that promotes the healthy development of each infant.

The IMH-HV therapist draws parental attention to the infant's developmental and relational needs by offering careful comments like "You are the one who is important to him...you are the one who can make him laugh" (Weatherston, 1995). Comments that promote reflection and attention to specific developmental milestones help to predict the next developmental phase, such as, "Wow, he is pointing at things, wanting you to tell him their names! Soon he will have so many more words." The IMH-HV visitor does not comment on relational qualities that do not exist, but rather watches for subtle behaviors, movements, and interactions that might otherwise be missed. In this way, the centrality of the parent to the infant is reinforced and elaborated. For parents who have never felt special or loved, coming to understand that their baby looks to them for interaction, reassurance, and permission to explore holds powerful promise, shoring up the parent's understanding of his/her importance to the child as well as the child's developing capacities.

This article is protected by copyright. All rights reserved. 
In contrast to home visiting programs that rely on modeling as a significant part of service delivery (Hebbeler \& Gerlach-Downie, 2002), the IMH-HV therapist rarely intervenes directly with an infant or young child, unless safety warrants it. Most optimally, with fidelity to the model in mind, the therapist is trained to sit beside the parent and child together, learning about the quality of their relationship, with a focus on the infant's behavior and parent's response. Equally important is learning to listen to a parent's concern and treating it honestly and respectfully. The IMH-HV therapist notices and wonders what the infant brings to the relationship (the smiles, the coos, the enthusiastic babbles, the capacity to engage in playful response, or none of these). With parents who seem not to notice these cues, the goal is to help parents take delight in their child and call attention to the ways in which the baby's bids for interaction or reassurance promotes the growth of a secure attachment and optimal development (Sameroff, 2004). It is equally important to notice what the parent brings to the care of the infant (gentle handling, a comforting touch, initiation of a game, sensitive response, or not). Many developmental activities that are suggested, e.g., peek-aboo, songs, etc., are shared with the parent in the presence of the infant or toddler and are designed to promote positive interaction and pleasure in the relationship. The evidence base for the role of shared pleasure in development indicates that increased duration of moments of shared pleasure in early infancy is significantly predictive of lower rates of anxiety, depression or aggression at 24 months (Mäntymaa et al., 2015). Attending to and supporting positive emotional valence and reciprocity of the dyad is particularly important in assisting the baby to develop positive emotion regulation strategies. Schore (2017) urges the field of infant mental health to attend to the neurobiological research that demonstrates the profound negative impact of persistent dyssynchronous parent-child interactions on the developing infant brain, labeling it "relational attachment trauma" (Schore, 2017, pg. 33). Further, he draws our attention to the nature of the development of the male infant brain and its particular vulnerability to mis-attuned interactions. Thus, promoting positive and reciprocal interactions is an essential task of the IMH-HV therapist.

This article is protected by copyright. All rights reserved. 
IMH-HV therapists are also prepared to notice, wonder about, and respond to challenging behaviors, difficult interactions, or parental worries. Notably, the IMH-HV does not offer praise for parenting strengths while ignoring parenting vulnerabilities. The available evidence suggests that attending only to strengths, in the face of significant difficulties, does little to change parenting beliefs or behaviors that are problematic (Hebbeler \& Gerlach-Downie, 2002). Through training and reflective supervision, the IMH-HV therapist becomes skilled at observing and noting areas of parental behavior or interaction that are more difficult or may create fear, alarm or distress, e.g. teasing that leaves the baby feeling helpless or overstimulated (Fraiberg,1974). Equally important, the therapist is advised to acknowledge his or her own discomfort when observing an interaction that is troubling or may be disruptive to the relationship or the baby's development, wonder about it, discuss its meaning during supervision, and, as appropriate, gently address the behavior with the parent. The capacity to offer such input in this way is in part reliant on the strength of the alliance between the parent and the IMH-HV therapist, as well as the support offered to the therapist through reflective supervision.

\section{Infant-parent psychotherapy}

A critical component in the Michigan IMH-HV model, infant-parent psychotherapy (IPP) recognizes that parental behavior may be influenced by parental experiences of loss, separation, abandonment, family violence or neglectful or abusive care (Shapiro, Adelson \& Tableman, 1980). Infant-parent psychotherapy nurtures the exploration of past and present salient relationship experiences and how they connect to the here and now (Fraiberg, et al., 1975; Lieberman \& Pawl, 1993).

Some parents need only the presence of the IMH-HV therapist and modest support to successfully strengthen their capacities to respond to their children with warmth and enter into a nurturing relationship. Other families need more help in understanding their caregiving responsibilities, their babies' distress, the meaning of a particular behavior or the importance of This article is protected by copyright. All rights reserved. 
their caregiving to their babies' health and growth. Infant-parent psychotherapy invites parents to share thoughts and feelings about the baby, caregiving responsibilities, and relationship experiences with the IMH-HV therapist. Early or unresolved maternal or paternal losses, prolonged separations from caregiving figures, maternal deprivation, and trauma leave physical or emotional scars and may make it difficult for a parent to care for a child as other life experiences may also impose challenges on a new mother/parent (poverty, lack of family support, mental health concerns, etc.). The IMH-HV therapist supports the parent in having access to and tolerating feelings associated with painful past experiences, and in so doing, also helps to separate those past feelings and experiences from present experiences in the here-and-now with the baby (Ghosh Ippen, 2019; Slade, 2014).

Essential to the work is the understanding that in the presence of the infant, a parent's memories attached to difficult past experiences may be awakened with intensity, making care for the baby extraordinarily difficult. Parents often express psychological conflicts, ambivalence, helplessness or hostility about parenting without words, instead speaking through their interactions with their baby (Fraiberg, 1974; Lieberman \& Van Horn, 2008). Pausing to think about the meaning that lies behind infant behavior, parental response or an interaction between the two, is an important strategy in the Michigan IMH-HV model. Thus, IPP, in the context of the array of IMH services, draws attention to the meaning of the baby to the parent and assists parents to understand and nurture their baby. The presence of the baby is essential in that $\mathrm{s} /$ he often elicits powerful feelings and conscious and unconscious memories, organizes the focus of the work, and contributes to the understanding of parental dilemmas through her/his actions, reactions, and capacity or lack thereof, to achieve developmental milestones (Wright, 1986).

Central to IPP is the belief that the baby in the room "may represent a cast of characters who were neglectful, abusive, rejecting or abandoning and who now threaten to intrude this nursery" (Weatherston \& Tableman, 2015, p. 184). The infant's presence is a catalyst; most parents are motivated, consciously or unconsciously to provide something different for their child if their 
own histories were fraught (Fraiberg, Shapiro, \& Cherniss, 1980). The infant remains central because her/his presence may elicit intense emotions as parents struggle to recall their own early sorrow, loneliness, fear, helplessness, anxiety, and anger. The baby, caught in a family drama, past or present, may be perceived by the parent as the one now rejecting or filled with rage, thus the baby may serve as a projection field for past events, sorrows and protagonists (Bowlby, 1940; Bowlby, 1969/1982). Conversely, some children construct idealized models of their parents to protect themselves from the reality of the harshness of their family situation. As parents, they may idealize their own child, failing to acknowledge the range and complexity of feelings that infants can arouse. In so doing, they can fail to recognize and allow their child to express a wide range of positive and negative emotions (Fraiberg, 1980).

Weatherston (2001), suggests that, "The infant allows a story to be told. The way in which a parent handles the baby, gestures of care, playful interaction or the absence of interaction suggest to the therapist what is going well but also what some of the conflicts, as yet unexpressed, might be (p.374)." The infant's crying, smiling, gazing, reaching, moving, sleeping, sucking and eating, cooing and babbling all offer powerful messages that beg for understanding from the parent. The IMH-HV therapist pays special attention to the cues, miscues, and interactions between the parent and infant, as their "dance" is a unique form of communication. In the encyclopedia Infancy in America, Honig, Fitzgerald \& Brophy-Herb (2001) define the task of IPP as careful attention to:

The experience and exploration of feelings that threaten appropriate and affectionate parental response; questioning that offers a parent the opportunity to wonder, reflect, recall and understand reactions; supportive listening; the clarification of thoughts and feelings a parent has; and, empathic response (p. 371).

The therapist asks questions that invite recollection, "Who would have held you when you were upset? What happened when you were frightened? Who would have soothed you when you were sick or tired?" Particularly when parents have incurred abuse, pain and terror at the hands of their 
own caregiver, naming those emotional experiences are particularly powerful. Slade (2014) notes,

"As fear is imagined and named by the therapist, and gradually tolerated and accepted by the

patient, compassion and forgiveness are mobilized in both" (p. 260). As stories of early pain emerge, and are met repeatedly with empathic understanding (Bowlby, 1940), kind words, and validation, parents are often freed to recall more tender moments in their own childhood, i.e., angels in their nursery (Wright, 1986; Lieberman, Padrón, Van Horn \& Harris, 2005). Having access to memories of moments of feeling special, loved, safe or protected helps parents offer the same to their child. For parents who have precious few of these recollections, the IMH-HV therapist strives to provide new emotional experiences of care, concern, and reliable sensitivity. They become the "safe base" from which the parent can explore new ways of understanding and responding to their baby. Parents who "feel felt" (Furman, 1992), who experience their therapist as deeply understanding and accepting of them, develop new procedural memories (Stern, et al., 1998) so they can offer the same to their baby. Known as the "platinum rule" of IMH practice, "Do unto others as you would have others do unto others" (Pawl \& St. John, 1998), it is the parallel process by which the IMH-HV therapist seeks to help the parent develop a new relational template.

The concept of parallel process informs clinical practice in conceptual and concrete ways. For example, a mother who was neglected as a baby and is lonely, isolated, and emotionally depleted as an adult may have difficulty noticing and responding to her baby's cues of hunger. The $\mathrm{IMH}-\mathrm{HV}$ therapist may bring soup or a sandwich for the mother (and any older children) to the home visit, in order to concretely and metaphorically give her the experience of being fed, with the understanding that the mother needs to feel fed in order to feed. The process of explicitly and symbolically meeting the concrete and psychological needs of the parent, repeated throughout the course of the relationship, offers hope that the baby will experience more reliable and safe caregiving than the parent had as a child. Because attachment theory suggests that relational 
templates can be transmitted through generations (Lyons-Ruth, et al. 2003; Sroufe, et al., 2005;

Raby \& Dozier, 2019), the IMH-HV Model may also be protective for future generations.

At times, the relational harm and emotional barrier are not rooted in early childhood but in current circumstance. An adolescent mother who is rejected by her own parents because of the pregnancy and abandoned by the baby's father may well struggle to fall in love with her baby as his or her presence may represent all that the mother has lost. Parents who have been relationally injured need to experience sensitive care in order to offer the same to their babies. Parenting patterns rooted in one's own history and experiences are not easily altered by information alone; one must feel seen to see, feel understood to understand, feel cared for to care.

In summary, these 6 core intervention strategies or components were integral to the early work of Selma Fraiberg and her interdisciplinary team of IMH specialists (Fraiberg, 1980) and continue to be central to the work of Michigan IMH-HV therapists today. This framework guides IMH-HV therapists to support developmental and clinical needs in the infant's first years of life and reduce the risk of delays or disorders of infancy due to parental histories of trauma, unresolved loss, parent mental health issues, domestic violence, abuse and neglect. In everyday practice and over the course of an IMH-HV intervention, some or all of these strategies may be appropriate to the needs of individual infants, toddlers and families. Together, these form an effective set of IMH-HV strategies that contribute to growth and change for the parent, the infant, and their relationship and are used consistently by therapists (see Huth-Bocks et al., this issue).

\section{Reflective Supervision}

Throughout all the developments in cognitive systems and language, emotions hold the self together...

Trevarthen, 2001, p. 114

This article is protected by copyright. All rights reserved. 
As may be surmised, becoming an IMH-HV therapist requires specific academic and professional training. Most optimally, masters or doctoral prepared IMH-HV therapists have a strong knowledge of infant development, attachment theory, cultural humility, adult mental health, substance use disorders, and psychopathology; opportunities to develop strong assessment skills and strategies for IMH-HV relationship centered intervention; and, reflective practice experiences that emphasize a strong awareness of self and others. However, academic preparation alone rarely suffices. What enables the IMH-HV therapist to retain the capacity for the observation, empathy, compassion and responsivity that defines the model, holding the baby, the parent, and multiple relationships in mind? The experience of reflective supervision, wherein the therapist is heard and accepted in tangling with the emotional complexity of IMH-HV, enables the search for greater understanding of the infant, the parents, and of oneself. The therapist is required to feel and understand the emotions of the baby and the struggles of the parent, all the while regulating his/her own emotions and reactions. Precisely because emotional development is a central task of infancy, the glue that transforms domains of development into each baby's unique sense of self, supporting parental capacity to hold and contain emotions is central to the Michigan IMH-HV model (Winnicott, 1968/2002; Gergely \& Watson, 1999). It is no small feat to master the skills necessary to observe interactions, often quite painful ones, wonder about them, and to respond with consistent kindness, empathy, compassion, and insight to the needs of a particular family. Just as a young child develops his/her emotional world best in the space of "feeling felt with" (Furman, 1992, p. 69), the IMH- HV therapist develops his/her capacity to be open, curious and reflective and to respond sensitively and with empathy within the reflective supervisory relationship. Most optimally, the RS relationship offers a place to have and examine reactions, to share joys and worries, to explore ways of responding and to feel felt with as one explores the complex work of IMH-HV. Yet, full understanding of reflective supervision (RS) is often elusive and challenging to define. Not a coaching model, not individual psychotherapy, not solely clinical supervision (Watson, Harrison, Hennes and Harris, 2016;

This article is protected by copyright. All rights reserved. 
Shafer, 2007), RS draws on all of these to create a unique experience for the IMH-HV therapist. It has been and continues to be central to the Michigan IMH-HV model.

Intentionally not proscriptive, reflective supervision offers a relationship within which the $\mathrm{IMH}-\mathrm{HV}$ therapist and supervisor attend to "the real work with vulnerable infants and families as well as the personal thoughts, feelings, and memories that are aroused in response to the work" (Tomlin, Weatherston \& Pavkov, 2014). Rooted in the evidence that reflective capacity is core to understanding the feelings, wishes, values, beliefs and motivations of self and others, and using that understanding to formulate responses (Fonagy, Steele, Steele, Moran \& Higgit, 1991; Slade, 2005; Suchman, DeCoste \& Mayes, 2009; Cologon, Schweitzer, King \& Nolte, 2017), RS offers the IMH-HV therapist a place to insure he/she is retaining empathic awareness of the baby, the parents, and the relationship between them, as well as space for self-reflection.

In addition to supporting these capacities, RS attends to "parallel process," i.e., the ways in which relational experiences impact the entire system; what is happening between the baby and parent may also be experienced by the therapist in interaction with the parent and between the therapist and the supervisor (Gallese, Eagle, \& Mignon, 2007; Shea, this issue; Tomlin \& Heller, 2016; Ribaudo, 2016; Watson et al., 2016). Sensitively attuned IMH-HV therapists often absorb the unspoken, unprocessed experiences of the parent and/or infant, leaving the home visit with the residual feelings of the same loneliness, despair, rage or sadness that members of the family are suffering. Those affects, if attended to in supervision, allow for a deeper understanding of what may need to be acknowledged in the therapeutic work. For example, a therapist may leave a home visit feeling particularly bereft, having watched a baby struggle alone in a car seat with little parent-infant interaction over the course of the visit. The therapist might feel aligned with the baby, failing to notice how lonely and distant the parent felt in the course of the visit. Through the sharing of affective states (Gallese, et al., 2007; Gallese, 2014; Lamm \& Majdandžić, 2015), it is theorized that a sensitive reflective supervisor might notice the IMH-HV therapist's subtle cues of loneliness and

This article is protected by copyright. All rights reserved. 
emotional isolation in talking about the family. By offering the opportunity to explore what was felt in the presence of the baby and parent/s, e.g., loneliness, the supervisor and supervisee have the opportunity to apprehend the loneliness that the infant and the parent/s may be experiencing. With newfound understanding, the IMH-HV has renewed empathy for the infant and the parent, and new strategies to explore on the next home visit that will perhaps alleviate their deep sense of loneliness and isolation from one another. Recognition of the parent's feelings by the IMH-HV therapist may allow the parent to feel less lonely and, similarly, may help the parent respond to the infant's need for attention and affection. In the absence of supervision that invites attention to emotion and to the experiences of the IMH-HV therapist while with the infant and family, there is a heightened risk that the therapist will fail to recognize or respond to the emotional complexity and ambiguity of the clinical work (Jen Der Pan, Deng, \& Tsai 2008). As noted in Shea's article in this issue, the trust in and use of the supervisory relationship is also associated with decreases in job burn-out and increases in work satisfaction (Shea, this issue). Important to understand, without emotional safety, consistency, honesty and dependability, the trust necessary for the supervisee to share his/her experience with the supervisor may not develop (Weatherston \& Barron, 2009; Watson, et al., 2016).

\section{Summary and Conclusions}

In summary, the Michigan IMH-HV Model, with its multiple intervention strategies, provides infants, toddlers, and their parents a range of services and experiences, offered in a careful, sensitive fashion, designed to promote and enhance the developing parent-infant relationship. IMH-HV offers support to a variety of parents, such as those with "good enough" histories and circumstances as they devote the energy to learning about their new babies. The Michigan model of IMH-HV also provides a safe, responsive, and attentive therapeutic relationship to infants and their parents when the adults have been relationally harmed, whose own histories have not included "good enough" caregivers, or who are parenting in highly stressful and impoverished environments. Offered in the 
home setting, as it has been in Michigan for decades, the IMH-HV Model offers the family the opportunity to tell their story in their own way, on their terms, not in the confines of an office

setting. In much the same way that the parent is required to go to the baby, the IMH therapist goes to the parent, both concretely and symbolically, generating a new experience of relationship. In the offering of an attuned therapist, where vulnerabilities and capacities, sorrow and joy, connection and autonomy are noticed and acknowledged, a parent may, perhaps for the first time, feel seen, heard and understood and thus be fueled to offer the same for their baby.

Across the core components elaborated above, relationships are the linchpin, the force that binds infant to parent, parent to therapist and therapist to supervisor. Connecting the past to the present, embedded in the model, is the belief that sensitive intervention in the early years of life hold great potential for promoting infant mental health and wellbeing for the current baby and for generations of infants to come (Bowlby, 1940; Fraiberg, 1980, Raby \& Dozier, 2019).

This article is protected by copyright. All rights reserved. 


\section{REFERENCES}

Ash, J. \& Williams, M.E., (2016). Policies and systems support for infant mental health in the care of fragile infants and their families. Newborn \& Infant Nursing Reviews, 16, 316-321.

Benoit, D., Zeanah, C. H., Parker, K. C. H., Nicholson, E., \& Coolbear, J. (1997). “Working model of the child interview": Infant clinical status related to maternal perceptions. Infant Mental Health Journal, 18, 107-121.

Bowlby, J. (1940). The Influence of Early Environment in the Development of Neurosis and Neurotic Character. The International Journal of Psychoanalysis, 21,154-178.

Bronfenbrenner, U. (1979). Contexts of child rearing: Problems and prospects. American Psychologist, 34, 844-850.

Brown, C. W. (2009). Selma Fraiberg. Jewish Women in America: A Comprehensive Historical Encyclopedia. Jewish Women's Archive. Retrieved from https://jwa.org/encyclopedia/article/Fraiberg-Selma

Cologon, J., Schweitzer, R.D., King, R., Nolte, T. (2017). Therapist reflective functioning, therapist attachment style and therapist effectiveness. Administration and Policy in Mental Health and Mental Health Services Research, 44, 614-625.

Fonagy, P., Steele, H., Moran, G., Steele, M., \& Higgitt, A. (1991). The capacity for understanding mental states: The reflective self in parent and child and its significance $f$ or security of attachment. Infant Mental Health Journal, 13, 200-217.

Fraiberg, S. (Ed.). (1980). Clinical Studies in Infant Mental Health: The First Year of Life. New 
York, NY: Basic Books, Inc.

Fraiberg, S. (1974). The Clinical Dimension of Baby Games. Journal of the American Academy

of Child Psychiatry, 13, 202-220.

Fraiberg, S., Adelson, E., \& Shapiro, V. (1975). Ghosts in the nursery: A psychoanalytic approach to the problems of impaired infant-mother relationships. Journal of the American Academy of Child and Adolescent Psychiatry, 14, 387-421.

Furman, E. (1992). On feeling and being felt with. The Psychoanalytic Study of the Child, 47, 67-84.

Gallese, V. (2014). Bodily selves in relation: embodied simulation as second-person perspective on intersubjectivity. Philosophical Transactions of the Royal Society B: Biological Sciences, 369, 1-10.

Gallese, V., Eagle, M.N., \& Migone, P. (2007). Intentional attunement: Mirror neurons and the neural underpinnings of interpersonal relations. Journal of the American Psychoanalytic Association, 55, 131-176.

Gergely, G. \& Watson, J. (1996) The social biofeedback model of parental affective mirroring. International Journal of Psychoanalysis 77: 1181-212.

Ghosh Ippen, C.M. (2019). Wounds form the past: Integrating historical trauma into a multicultural infant mental health framework. In C.H. Zeanah (Ed.) Handbook of infant mental health (4 ${ }^{\text {th }}$ ed.) (135-153). New York, NY: Guilford Press.

Gomby, D.S., Culross, P.L., \& Behrman, R.E. (1999). Home visiting: Recent program evaluations-analysis and recommendations. The Future of Children: Home Visiting: Recent Program Evaluations, 9, 4-26.

This article is protected by copyright. All rights reserved. 
Harding, K., Galano, J., Martin, J., Huntington, L., \& Schellenbach, C. J. (2007). Healthy Families America effectiveness: a comprehensive review of outcomes. Journal of Prevention \& Intervention in the Community, 34, 149-179.

Hebbeler, K.M. \& Gerlach-Downie, S.G. (2002). Inside the black box of home visiting: A

qualitative analysis of why intended outcomes were not achieved. Early Childhood Research Quarterly, 17, 28-51.

Honig, A.S., Fitzgerald, H. \& Brophy-Herb, H. (Eds.) (2001), Infancy in America: An Encyclopedia (Vo. 1). Santa Barbara, CA: ABC-CLIO.

Irving Harris Foundation Professional Development Network Tenets Working Group (2018).

Diversity-informed tenets for work with infants, children and families. Retrieved from https://imhtenets.files.wordpress.com/2018/04/tenetsspanishenglish2ndedition2018.pdf

Jen Der Pan, P., Deng, L.-Y., \& Tsai, S.-L. (2008). Evaluating the Use of Reflective Counseling Group Supervision for Military Counselors in Taiwan. Research on Social Work Practice, 18, $346-355$.

Knox, J. (2016). Epistemic mistrust: A crucial aspect of mentalization in people with a history of abuse? British Journal of Psychotherapy 32, 226-236.

Lamm, C., \& Majdandžić, J. (2015). The role of shared neural activations, mirror neurons, and morality in empathy--a critical comment. Neuroscience Research, 90, 15-24.

Lawler, J.M., Rosenblum, K.L., Muzik, M., Ludtke, M., Weatherston, D.J., Tableman, B. (2017). A Collaborative Process for Evaluating Infant Mental Health Home Visiting in Michigan. Psychiatric Services, 68, 535-538.

Lieberman, A.F. (2004). Child-parent psychotherapy: A relationship-based approach to the This article is protected by copyright. All rights reserved. 
treatment of mental health disorders in infancy and early childhood. In A.J. Sameroff, S.C. McDonough \& K.L. Rosenblum (Eds.). Treating parent-infant relationship problems (97-122). New York: Guilford Press.

Lieberman, A.F. \& Pawl, J.H. (1993). Infant-parent psychotherapy. In C.H. Zeanah (Ed.), Handbook of Infant Mental Health (427-442). New York, NY: Guilford Press.

Lieberman, A.F., \& Van Horn, P. (2008). Psychotherapy with Infants and Young Children. New York, NY: Guilford Press.

Lieberman, A. F., Padrón, E., Van Horn, P., \& Harris, W. W. (2005). Angels in the nursery: The intergenerational transmission of benevolent parental influences. Infant Mental Health Journal, 26, 504-520.

Lieberman, A. F. \& Van Horn, P. (2004). Don't Hit My Mommy! A Manual for Child-Parent Psychotherapy with Young Children. Washington, D.C.: National Center for Clinical Infant Programs.

Lieberman, A. F., Ippen, C. G., \& Van Horn, P. (2015). Don't Hit My Mommy! A Manual for ChildParent Psychotherapy With Young Children Exposed to Violence and Other Trauma (2nd ed.). Washington DC: Zero to Three Press.

Lieberman, A. F., Van Horn, P., Ippen, C.G. (2005). Toward evidence-based treatment: childparent psychotherapy with preschoolers exposed to marital violence. Journal of the American Academy of Child and Adolescent Psychiatry, 44, 1241-1248.

Lowell, D.I., Carter, A.S., \& Godoy, L., Paulicin, B., \& Briggs-Gowan, M.J. (2011). A randomized controlled trial of Child FIRST: A comprehensive home-based intervention translating research into early childhood practice. Child Development, 82, 193-208.

This article is protected by copyright. All rights reserved. 
Lyons-Ruth, K. (1996). Attachment relationships among children with aggressive behavior problems: The role of disorganized early attachment patterns. Journal of Consulting and Clinical Psychology, 64, 64-73.

Lyons-Ruth, K., Yellin, C., Melnick, S., \& Atwood, G. (2003). Childhood experiences of trauma and loss have different relations to maternal unresolved and Hostile-Helpless states of mind on the AAl. Attachment \& Human Development, 5, 330-352.

Mäntymaa, M. Puura, K., Luoma L., Latva R., Salmelin R.K., \& Tamminen, T. (2015). Shared pleasure in early mother-infant interaction: Predicting lower levels of emotional and behavior problems in the child and protecting against the influence of parental psychopathology. Infant Mental Health Journal, 36, 223-237.

McDonough, S.C. (2004). Interaction guidance: Promoting and nurturing the caregiving relationship. In A.J. Sameroff, S.C. McDonough \& K.L. Rosenblum (Eds.). Treating parent-infant relationship problems (79-96). New York: Guilford Press.

McKelvey, L., Schiffman, R. F., Brophy-Herb, H. E., Bocknek, E. L., Fitzgerald, H. E., Reischl, R. M., Hawver, S., \& DeLuca, M. C. (2015). Examining long-term effects of infant mental health home-based Early Head Start program on family strengths and resilience. Infant Mental Health Journal, 36, 353-365.

Pawl, J. (1984). Strategies of intervention. Child Abuse \& Neglect, 8, 261-270.

Pawl, J. \& St. John, M. (1998). How you are is as important as what you do. In Making a Positive Difference for Infants, Toddlers and their Families. Washington, D.C.: Zero to Three.

Puig, J., Englund, M.M., Simpson, J.A., Collins, W.A. (2013). Predicting adult physical illness from infant attachment: A prospective longitudinal study. Health Psychology, 32, 409-417.

Raby, K. L., Lawler, J. M., Shlafer, R. J., Hesemeyer, P. S., Collins, W. A., \& Sroufe, L. A. (2015). The interpersonal antecedents of supportive parenting: A prospective, longitudinal study from infancy to adulthood. Developmental Psychology, 51, 115-123.

This article is protected by copyright. All rights reserved. 
Raby, K.L., \& Dozier, M. (2019). Attachment across the lifespan: insights from adoptive families. Current Opinion in Psychology, 25: 81-85.

Ribaudo, J. (2016). Restoring safety: An attachment-based approach to clinical work with a traumatized toddler. Infant Mental Health Journal, 37, 80-92.

Rosenblum, K.L., Muzik, M. Jester, J., Huth-Bocks, A., Erickson, N., Ludtke, M., ...Waddell, R. (under review). Community-delivered publicly-funded infant-parent psychotherapy improves sensitive caregiving: Evaluation of the Michigan model of infant mental health home visiting.

Sadler, L.S., Slade A., Close, N., Webb, D.L., Simpson, T., Fennie, K., \& Mayes, L.C. (2013). Minding the Baby: Enhancing reflectiveness to improve early health and relationship outcomes in an interdisciplinary home-visiting program. Infant Mental Health Journal, 34, 391-405.

Sameroff, A. J. (2004). Ports of entry and the dynamics of mother-infant interventions. In A.J. Sameroff, S.C. McDonough \& K.L. Rosenblum (Eds.), Treating parent-infant relationship problems (3-28). New York, NY: Guilford Press.

Schore, A.N., (2017). All our sons: The developmental neurobiology and neuroendocrinology of boys at risk. Infant Mental Health Journal, 38, 15-52.

Shapiro, V. (2009). Reflections on the work of Professor Selma Fraiberg: A pioneer in the field of social work and infant mental health. Clinical Social Work Journal, 37, 45-55.

Shapiro, V., Adelson, E., \& Tableman, B. (1980). Beginning at the beginning: The introduction of infant mental health services to community mental health. In S. Fraiberg, (Ed.), Clinical studies in infant mental health: The first year of life. New York, NY: Basic Books, Inc.

Sherman, L.J., Rice, K. \& Cassidy, J. (2015). Infant capacities related to building internal working models of attachment figures: A theoretical and empirical review. Developmental Review, $37,109-141$.

Slade, A. (2005). Parental reflective functioning: An introduction. Attachment \& Human Development, 7, 269-281.

This article is protected by copyright. All rights reserved. 
Slade, A. (2014). Imagining fear: Attachment, threat and psychic experience. Psychoanalytic Dialogues: The International Journal of Relational Perspectives, 24, 253-266.

Sroufe, L.A., Egeland, B., Carlson, E.A., \& Collins, W. A., (2005). The development of the person: The Minnesota study of risk and adaptation from birth to adulthood. New York, NY: Guilford Press.

Sroufe, L.A. (2013). The promise of developmental psychopathology: Past and present. Developmental Psychology, 51, 115-123.

Stern, D. N., Sander, L. W., Nahum, J. P., Harrison, A. M., Lyons-Ruth, K., Morgan, A. C., ...Tronick, E. Z. (1998). Non-interpretive mechanisms in psychoanalytic therapy. The "something more" than interpretation. The Process of Change Study Group. The International Journal of Psychoanalysis, 79, 903-921.

Stern, D. N. (2004). The motherhood constellation: Therapeutic approaches to early relational problems. In A.J. Sameroff, S.C. McDonough \& K.L. Rosenblum (Eds.), Treating parent-infant relationship problems (29-42). New York: Guilford Press.

Tomlin, A., Weatherston, D., \& Pavkov, T. (2014). Critical components of reflective supervision: Responses from expert supervisors in the field. Infant Mental Health Journal, 35, 70-80.

Trevarthen, C. (2001). Intrinsic motive for companionship in understanding: Their origin, development and significance for infant mental. Infant Mental Health Journal, 22, 95131.

Watson, C., Harrison, M., Hennes, J., \& Harris, M. (2017). Reflective Interaction Observation Scale (RIOS) Manual. St. Paul, MN: University of Minnesota, Center for Early Education \& Development.

Weatherston, D.J. (1995). She does love me, doesn't she: A story of longing, waiting and 
responding. Zero to Three, 15, 6-10.

Weatherston, D. \& Tableman, B. (1989). Infant mental health home visiting. Southgate, MI: Michigan Association for Infant Mental Health.

Weatherston, D. \& Tableman, B. (2015). Infant mental health home visiting (3rd ed.). Southgate, MI: Michigan Association for Infant Mental Health.

Weatherston, D. and Barron, C. (2009). What Does a Reflective Supervisory Relationship Look Like? In S. Heller \& L. Gilkerson (Eds.), A Practical Guide to Reflective Supervision (61-80). Washington, D.C.: Zero to Three.

Winnicott, D.W. (1968/2002). Communication between infant and mother, and mother and infant, compared and contrasted. Winnicott on the child (70-81). Cambridge, MA: Perseus Publishing.

Winnicott, D.W. (1971). Playing and reality. London: Tavistock Publications.

Wright, B. (1986). An approach to infant parent psychotherapy. Infant Mental Health Journal, 7, 247263. 